Natalia Sukhotska

\title{
INTERVIEW WITH LEV HRYTSIUK
}

Lev Hrytsiuk is a Ukrainian translator from Swedish, Norwegian, English and Russian languages. He is a compiler of The Anthology of Modern Swedish Poetry and the author of the blog WhyTranslator.

Please, define the words "translation" and "translator".

For me, translation is one of the most interesting activities from the aesthetic point of view. Artistic translation is a true art. A translator is a craftsman of the word.

\section{What are the tasks of a translator?}

A translator should convey the author's creative work as adequately as they can with the available means. Balancing between the language of the original and the language of the translation, understanding all the difficulty, and sometimes even the impossibility of the given task, they strive for perfect recreation of the original in the target language.

\section{Where do you usually find the original texst for your translation?}

If there is a publishing house interested in the translation, it sends a book (with its own funds) to the translator. I enjoy working with both paper and electronic versions of the text at the same time. I look for texts on the Internet, if I wish to translate something.

How does personal attitude of the translator towards the author influence the translation?

If you really like the author, it is always easier to translate. I have translated different authors, those whom I worship and those whom not. In fact, a text is a text, and it should not affect the quality of the final product.

Is it possible for the translation to be brighter than the original?

Of course, the translation can be brighter than the original. However, it is not always possible to define which text is better. And this uncertainty is definitely an advantage. For me as a translator, it is always interesting to compare originals to their translations; it is the so-called "game with beads".

While translating, what do you pay more attention to: the semantic accuracy of the translation or the stylistic equivalence?

Personally, I pay more attention to the semantic accuracy, but style is also very important. Sometimes, a translator feels that it is necessary to deviate from the original to better transmit the implied meaning. A translator always makes choices; a perfect translator always makes perfect choices.

\section{What translator is your role model?}

I am fond of Hryhoriy Kochur because his translations are genius, and you can learn from them the poetic translation as it is. Nowadays, among younger translators there are a lot of very interesting personalities. For example, I was impressed by the translations of Italian poetry by Taras Fedirko.

What is your favourite translation?

Self-translations of Samuel Beckett in English and French. In Ukraine - "The reverberation" by Hryhoriy Kochur.

(C) Sukhotska N, 2015 